Voix et Images

voixetimages

\title{
Quatre essais miniatures
}

\section{Jacques Brault}

Volume 12, numéro 2 (35), hiver 1987

Jacques Brault

URI : https://id.erudit.org/iderudit/200624ar

DOI : https://doi.org/10.7202/200624ar

Aller au sommaire du numéro

\section{Éditeur(s)}

Université du Québec à Montréal

\section{ISSN}

0318-9201 (imprimé)

1705-933X (numérique)

Découvrir la revue

\section{Citer ce document}

Brault, J. (1987). Quatre essais miniatures. Voix et Images, 12(2), 182-185.

https://doi.org/10.7202/200624ar d'utilisation que vous pouvez consulter en ligne.

https://apropos.erudit.org/fr/usagers/politique-dutilisation/ 


\title{
Quatre essais miniatures *
}

\author{
par Jacques Brault
}

\section{Un lieu d'écriture}

Le lieu de l'écriture ne se décrit pas. On l'évoque comme une patrie perdue, on l'invoque comme un paradis de nulle part. Qui peut prétendre l'habiter? Parmi les écrivains, il s'en trouve qui écrivent pour prolonger ces rares instants de grâce où le monde ambiant se dérobe pour faire place à un autre monde, à ce lieu innommable de l'écriture et où le temps ne coule plus dans le même sens qu'à l'ordinaire.

On entre en écriture, on entre en état de possession. Les anciens calligraphes chinois commençaient par frotter un bâtonnel d'encre sur une pierre mouillée. Cela durait longtemps; cela permettait de se recueillir et, n'ayant plus que soi-même pour bagage, de s'eń aller ailleurs, vers la blancheur énigmatique du papier. Le moment 'venu, l'écrivain trempait son pinceau dans le lait noir et laissait couler les signes. Il oubliait tout, il se méprenait sur tout. Il écrivait.

Georges Perros fait songer aux Chinois. Il marche à tâtons, il essaie de rejoindre l'aut re côté du langage. Par les moyens les plus économes. Car il est pauvre. Opéré d'un cancer au larynx, il n'a plus vraiment qu'à écrire. Loin de s'enfermer dans son malheur ou de se mirer dans un ciel à douteuse figuration, il écrit avec la droiture et la gravité de celui à qui les jours sont comptés pour la dernière fois. Il multiplie les poèmes et les portraits, les aphorismes, les fragments de lettres et de journal, il écrit dans l'exactitude de sa tendresse âpre et généreuse. Toute son œuvre, au fur et à mesure des publications posthumes, prend l'allure d'une longue missive envoyée de loin aux amis inconnus.

Écrire à quelqu'un : c'est une définition de la lettre. Mais comment peut-on ne pas écrire à quelqu'un? Les théories naguère à la mode assurent que l'écrivain ne s'adresse à personne. C'est vrai pour ce qui concerne le lieu même de l'écriture. C'est moins vrai si l'on pense que les mots et les phrases d'un écrivain viennent du tout-venant et qu'ils ne se forment en des enchainements nouveaux qu'à la faveur de la lecture. Si vous désirez n'écrire que pour vousmême et à vous-même, utilisez le téléphone; tout y est dit d'avance.

* Extraits d'un livre à paraître 


\section{Comme une visitation}

Ouvrir un livre comme on ouvre une fenêtre, oui, et se sentir pénétré par les odeurs, les clartés, les bruits, les froids et les chaleurs d'un monde naguère tenu à distance. Cela est beau et bon, ce plaisir d'une lecture qui se suffit à elle-même. Et ouvrir une lettre, et lire une lettre : comment qualifier le geste et l'occupation? On ne sait jamais ce qui va surgir de l'enveloppe qu'on tient entre les doigts. On tourne et retourne le rectangle de papier, on suppute, on devine presque.

Les écrivains qui écrivent à quelqu'un, à de véritables autres, amis ou étrangers, plutôt qu'à des succédanés d'eux-mêmes, ces écrivains pourraient tous sans erreur être considérés comme des épistoliers. Voici que la lettre n'est plus guère une forme d'écriture, mais que l'écriture devient une forme de lettre. Écrire, s'arracher ça, mais sans gloriole, Flaubert et Perros s'y entendent. Écrire, murmurer ou balbutier des merveilles toutes simples, Arland et Calet s'y entendent. Écrire, se reconnaître pauvre de mots et riche de cour, Gorki et Tchekhov s'y entendent. Écrire, allumer un éclair de malice au coin de l'cil éteint, Voltaire et Léautaud s'y entendent.

On pourrait poursuivre ainsi la liste d'un long appel de noms qui sonneraient comme autant de voix dans le chæur de ce qu'on appelle, hélas, littérature. Les livres voyagent comme les lettres et finisisent, tôt ou tard, par atteindre leurs vrais destinataires, qui ne sont jamais nombreux. On ouvre le livre, on ouvre la lettre, on ouvre la fenêtre, et d'un lointain proche arrive une nouvelle atlendue, inattendue: «Je vous écris pour vous dire...» Quoi donc? Peu importe, après tout. Bonnes ou mauvaises, les nouvelles répandues par les moyens d'information, qu'elles sont désuètes et racornies!

Mais par ce livre-lettre, par cette voix-fenêtre, voici bien la chose qui dérange et réarrange la monotonie existentielle. Un peu de langage, par quel mystère?, rajeunit ce qui a vieilli depuis le premier vagissement: "Je vous écris pour vous parler.... Solitude habitée, stupeur soulagée, qui êtes-vous donc en celle et celui qui n'attendaient plus rien ni personne?

Une lettre est arrivée, comme une visitation, et entre les larmes et les rires muets, on se lève, on sort de son immobilité, on marche à la porte, on ouvre. La suite sera ce qu'elle sera. On aura bonheur et malheur, et joie, et angoisse. Jusqu'à la dernière lettre: «Je vous écris pour que vous m'écriviez....» 


\section{Mine rien: tout}

De certains écrivains, on éprouve le besoin de préciser qu'ils sont des stylistes. Ce n'est pas toujours un compliment. Un livre dont le langage s'impose pour luí-même n'en est pas plus mauvais; ce qui gêne l'attention et déconcerte l'émotion, c'est la boursouflure, quand le style fait des bulles qui n'en finissent plus de crever à la surface des phrases. Le manque d'intériorité, voilà le défaut des qualités trop brillantes; et, partant, une lâcheté du lien qui devrait tenir serrées la parole et la pensée. On dit styliste comme on dit virtuose: qui dispense sur le champ une satisfaction énervée, épidermique.

Les œuvres qui restent, qui nous accompagnent et qui attendront notre possible retour, s'imposent par un langage inentamable. Les modes passeront, et les goûts, et les vérités reçues; la culture changera sous la poussée de l'histoire; le style juste, où la mort est la mère des formes, vivra aussi longtemps que les hommes. On le constate chez un Jacques Chardonne qui, au surplus, est un écrivain au style intimiste. L'harmonie et le dépouillement ne font jamais défaut à son lyrisme intérieur. Ni trop, ni trop peu, l'effet de style chez lui se remarque à peine, ou plutôt: le style ne s'impose pas, ne force pas l'adhésion. On lit et on ne s'aperçoit pas qu'on est envoûté. Témoin, cette phrase impossible à écrire si on n'a pas vécủ calmement le désespoir total et attentif à ce qui n'est pas lui - et si dù même coup on ne maîtrise pas son expression: «La vie a de violentes senteurs, et aussi des tons brouillés et des transparences où tout à coup elle nous montre qu'elle n'est rien». Des écrivains qui firent du bruit en leur temps s'étoufferont dans l'oubli; ils collaient à leur époque comme l'écorce à l'arbre. Chardonne continuera d'émouvoir pour peu qu'on le lise avec justesse: en lui demandant, plutôt que des sensations fortes et vite émoussées, des résonnances qui poussent leur pointe à travers notre endurcissement.

Tendresse, encore et toujours, oui, le style intimiste en vit, en meurt, et en renait. Il y a des déchirures de langage qui ne se produisent qu'à l'occasion d'une ferveur tempérée d'ironie, des déchirures qui exposent à la nostalgie notre confort intellectuel, des déchirures si profondes et si discrètes que soudain nos faux-semblants nous tombent dans les mains comme des larmes longues à force d'avoir été retenues par crainte du ridicule. Le style intimiste ne courtise pas l'extraordinaire. Il suit le tremblement léger de la vie qui s'en va entre naissance et mort, cherchant au cœur de l'orage une possible embellie. 


\section{Bonheur caché}

Constamment occupé par des amours malheureuses, devenu chauve et obèse, relégué dans un emploi médiocre, sans projet et sans fortune, vous vous demandez: "Qu'ai-je donc été?" Vous ne répondez pas; vous n'osez courir à nouveau le risque de vous égarer en raisonnant sur vous-même. Malgré tout, vous avez gardé une âme tendre et ardente, aux antipodes du sec et du froid qu'on vous impute. Et le bonheur à qui vous avez donné la chasse toute votre vie semble chose intouchable. Voici qu'il survient à l'improviste. Vous ne vous sentez pas heureux, vous êtes heureux. Parfaitement.

Cela qui fulgure et qui désenchaîne le temps peut emprunter les chemins du souvenir ou peut adopter l'apparence de l'accidentel. L'événement par lui-même n'a pas d'importance. Est-ce une certaine coloration du mur que chaque matin vous longez et qui offre soudain une luminescence subtile? Pareille douceur ramène au présent ce qui dans un passé presque évanoui vous avait marqué en profondeur. Vous n'aviez pas pris garde; vous n'aviez pas ressenti la secousse. Au demeurant, l'occasion ressemblait à beaucoup d'autres.' Et cet instant chargé d'un pur bonheur rassemble tout le dispersé, il établit une relation harmonique entre vos contraires.

Voilà donc le bonheur, petite ou grande chose qui fait battre plus vite le cœur, et qui n'a aucune connivence avec le sentiment de plaisir. Nulle attente n'a préparé sa venue. L'ennui et la déception alternant avec la passion et l'espoir ont rythmé vos jours et vos nuits. Vos ceuvres et vos entreprises visaient moins le succès qu'un durable accord avec vous-même. Mais vous vous ignoriez, vous ne connaissiez pas votre vrai nom, bien que vous fussiez attentif à ne pas être en dessous de vous-même. Vous n'a viez aucun penchant à la suffisance. L'ambition ne vous empêchait pas de dormir. Et les mondanités, assez modestes, auxquelles vous consentiez, ne comptaient que pour exercer l'esprit. Aux heures creuses, vous imaginiez parfois un bonheur solitaire, indépendant. Était-ce là cette vérité si chère pour qui vous imposiez silence à votre cceur?

Comme l'instant poétique par quoi tout se verticalise et devient simultané, l'instant de bonheur vous a pris à la gorge, vous laissant stupéfait. Plus que jamais étranger à vous-même, vous cherchiez à mettre au compte des objets ou des circonstances la sensation unifiante qui vous investissait. Mais lucide encore, vous perceviez la faille par où s'était engouffrée cette plénitude d'être; il ne vous échappait pas que le bonheur immérité, injustifiable, était comme apporté sur une vague de fond qui elle n'a rien d'heureux.

C'est ce qui vous a retenu d'écrire dans l'exaltation ou dans la fureur joyeuse. La chasse au bonheur était recherche de vérité impitoyable. Vos échecs ne se comptaient plus. Votre tristesse n'était pas feinte. On aurait pu faire de vous le portrait du raté. Malhabile à la réusșite, qui s'opère à coup de compromissions, l'amertume mouillant vos lèvres et vos yeux, vous poursuiviez votre chemin, un chemin d'oubli, de malaises physiques et moraux, et dont vous aperceviez, tout près, le dernier tournant.

Et soudain le bonheur a fondu sur vous sans crier gare. Vous vous y êtes reconnu, contre toute logique. Il était né de votre tristesse, il en était la face cachée. 


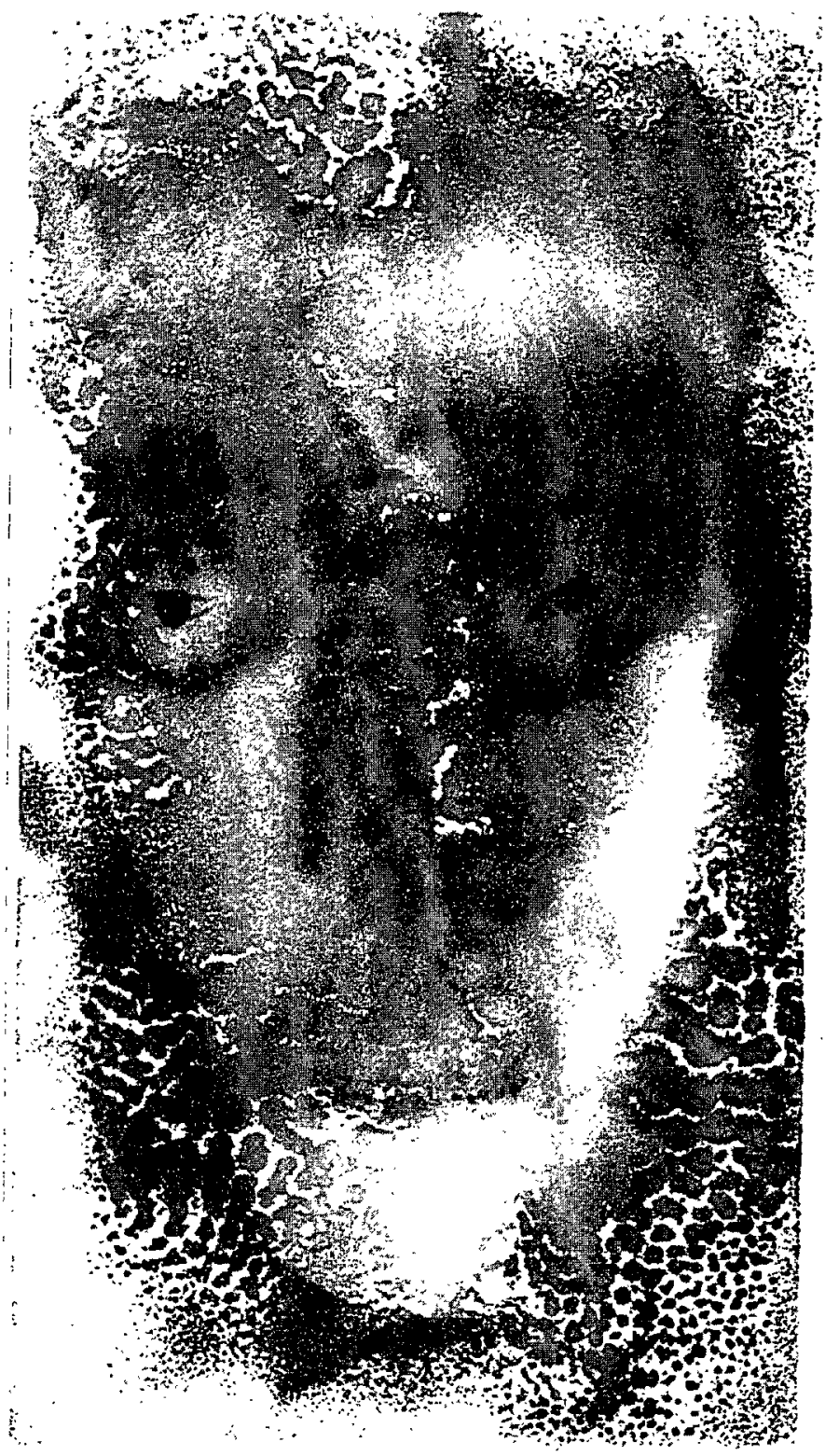

